\title{
Retuning the brain by learning, literature, and logic: Reply to Suga
}

\author{
Norman M. Weinberger ${ }^{1}$ \\ Center for the Neurobiology of Learning and Memory, University of California, Irvine, Irvine, California 92697-3800, USA; \\ Department of Neurobiology and Behavior, University of California, Irvine, Irvine, California 92697-3800, USA
}

Suga's Letter to the Editor in this issue (Suga 2008) is in response to my Review published in Learning \& Memory early last year (Weinberger 2007). He objects to my characterization and critique of the Gao-Suga model. He also argues that our model is wrong in positing a key role for the magnocellular medial geniculate/posterior intralaminar nucleus (MGm/PIN) of the auditory thalamus in learning-induced auditory cortical tuning shifts and behavior. However, Suga's letter does not actually defend the Gao-Suga model (Suga and Ma 2003) that I reviewed. Rather, he sets forth a new (previously unpublished) version, without so informing the reader. He then attempts to nullify my critique that his original model omitted the MGm/PIN by discussing his new model, which does incorporate these nuclei, albeit with dubious functions. This slight-of-hand and other sweeping claims preclude the possibility of an adequate response in this limited format because more space is needed to explain errors of fact and logic than to promulgate them. Thus, we cannot include an adequate review of Suga's revised model. Neither can an explication, defense, or summary of our model and its tested predictions be presented. Readers should consult the target article for such information about our model and for a broad review of auditory associative representational plasticity (Weinberger 2007).

\section{Reply to Suga's responses to Weinberger's comments on the Gao-Suga model}

In this section, I discuss each of the six points raised by Suga, but in an order different than he used. I indicate the serial number of his points in brackets, to facilitate cross-referencing between our two Letters.

\section{The magnocellular medial geniculate nucleus [4]}

Much of my critique of Suga's model involves the fact that it completely ignores the MGm/PIN. This component of the thalamic auditory system receives convergent auditory and somatosensory (shock) information and projects to all regions of the auditory cortex and to the lateral amygdala. Suga's response is to the effect that he didn't ignore the MGm (see more below). Figure 1A presents Suga's original model. Inspection shows that the MGm/PIN and its important connections to the auditory cortex and amygdala are absent. Thus, Suga's original model does ignore the MGm.

We can now consider Suga's revised model insofar as it includes the MGm/PIN (MGBm in his terminology). He argues that it is not involved in associative learning, particularly in fear conditioning. "Suga (2008) hypothesizes that the MGBm is involved in the non-specific plasticity (general augmentation) of cortical neurons elicited by unpaired CS and US (Fig. 1, dashed arrows) [Fig. 1 in his Letter], not in the tone-specific plasticity (BF shift) elicited by paired CS and US."

\section{'Corresponding author.}

E-mail nmweinbe@uci.edu; fax (949) 824-4576

Article is online at http://www.learnmem.org/cgi/doi/10.1101//m.914208.
If Suga is correct, then the MGm/PIN should exhibit plasticity to both a (tonal) conditioned stimulus (CS) and a (shock) unconditioned stimulus (US) during random or unpaired presentations. Moreover, according to Suga, the MGm should not develop associative plasticity, particularly CS-specific tuning shifts. Suga's hypothesis has already been tested repeatedly in many laboratories. The results are the opposite of his predictions. That is, the MGm develops CS-specific plasticity and tuning shifts only when an acoustic CS is paired with a US (e.g., shock); i.e., MGm plasticity is associative. In contrast, during sensitization, in which a tone and shock are not paired, specific plasticity does not develop in the MGm. These findings have consistently been replicated across laboratories and species. No studies have reported the results that are predicted by Suga's hypothesis. Table 1 summarizes the results of 25 studies of the MGm/PIN and conditioning.

Although he ignores the literature demonstrating associative plasticity in the MGm/PIN, Suga claims (earlier in his letter) that many laboratories have found tuning shifts ". . . without CSUS association in the MGBm and PIN." Suga cites 21 studies in support of his claim. One would then expect that at least some of these studies would have recorded in the $M G m / P I N$ during the formation of learning-induced auditory tuning shifts, and failed to find any associative plasticity therein. Unless such recordings were made in the MGm/PIN during learning, how could one conclude that there was no "CS-US association" in this part of the auditory thalamus? However, not a single study cited actually recorded in the MGm/PIN.

Six of the studies cited found conditioning-elicited tuning shifts in the inferior colliculus of the bat (Gao and Suga 1998, 2000; Ji et al. 2001, 2005; Ji and Suga 2003, 2007). But none of these studies recorded in the MGm/PIN. How can the development of plasticity in one brain region demonstrate that another brain structure does not develop plasticity? According to Suga's logic, it is not actually necessary to directly investigate a brain structure; one can eliminate it merely by finding plasticity elsewhere. This simply is illogical.

The remaining 15 cited studies all demonstrated that stimulation of brain sites can induce tuning shifts. For example, Suga cites three studies in which pairing a tone with electrical stimulation of the cholinergic nucleus basalis (NB) induces specific tuning shifts (Bakin and Weinberger 1996; Bjordahl et al. 1998) and specific frequency expansion in the primary auditory cortex (A1) (Kilgard and Merzenich 1998). We inaugurated NB stimulation studies to test an important aspect of our model (Weinberger et al. 1990a,b), viz., that during natural learning the NB releases acetylcholine $(\mathrm{ACh})$, which promotes long-term storage of information in the auditory cortex (Fig. 1B). Therefore, the fact that tone paired with NB stimulation does induce specific tuning shifts in the auditory cortex supports our model, and is admittedly the basis for Suga including the NB in his model (Gao and Suga 2000).

However, of greater importance for Suga's arguments, all of the stimulation studies are irrelevant to the issue of the MGm/ PIN. Reductionistic analysis is based on the ability to manipulate 
A.

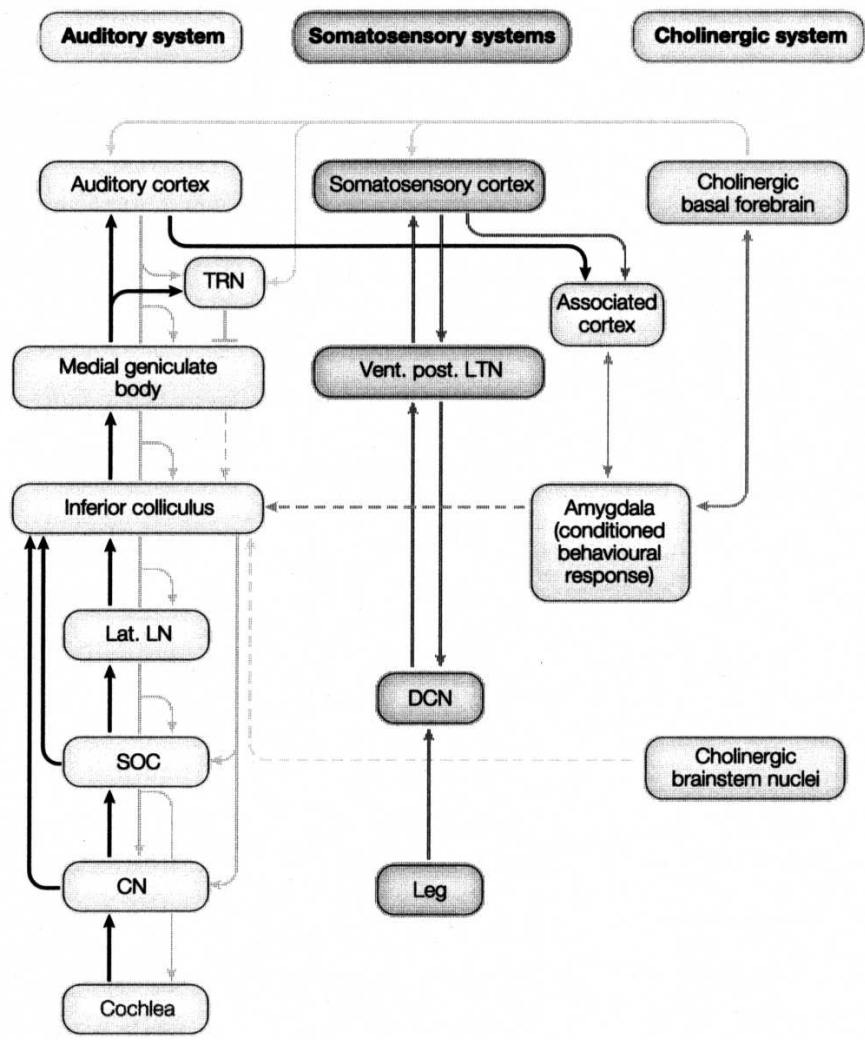

B.

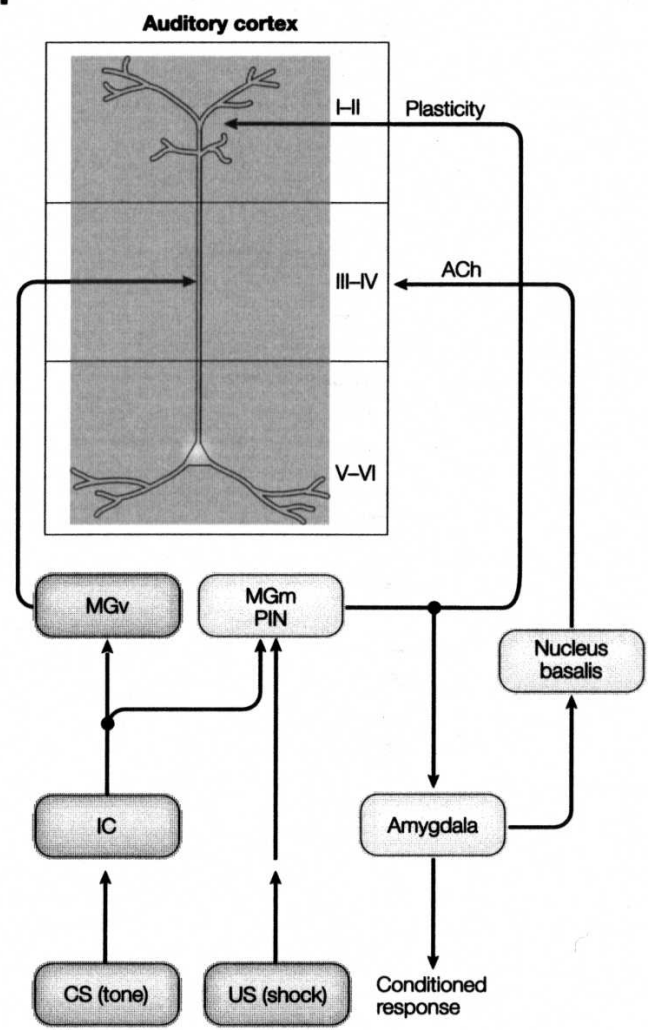

Figure 1. Models of auditory system retuning during fear conditioning. (A) The original Suga model (Suga and Ma 2003). Note the pathways for the tone CS and the shock US ascend to the auditory and somatosensory cortices, respectively, and first converge in association cortex. The MGm/PIN complex of the medial geniculate, which has long been established as a site of tone-shock convergence, is not included in this model. For a detailed analysis of this model, see Weinberger (2004b, 2007). For a related prior exchange of letters, see Suga et al. (2004); Weinberger (2004a). (B) The Weinberger and associates model (Weinberger 1998; Weinberger et al. 1990a,b). This model proposed the minimal circuitry that could account for CS-specific associative retuning of the primary auditory cortex and the elicitation of some behavioral signs of fear conditioning. Note that the cholinergic nucleus basalis is located "downstream" of ascending tone and shock information, which converges in the MGm/PIN. Cortical retuning is hypothesized to depend upon the convergence in A1 of (1) specific lemniscal auditory input conveying CS parameters to Layers III-IV, (2) MGm/PIN input to Layer I signaling subcortical association that promotes short-term retuning, and (3) cholinergic input that promotes long-term retuning. Reprinted from Weinberger (2004b), with permission from Nature Publishing Group $\odot 2004$.

components of a circuit to test a hypothesis. How can the induction of plasticity by stimulation of one brain region demonstrate that another brain structure does not develop plasticity? According to Suga's logic, one can eliminate a brain structure as normally being involved in a process merely by finding another brain region whose stimulation can induce the same process. Applying this type of reasoning to, e.g., audition, one would conclude that the ear is not normally involved in hearing because stimulation of the auditory nerve can produce sensations of sound.

\section{Tuning shifts to tone alone presentation [3]} and echolocating bat as general mammalian model [6] These two topics will be discussed together because the fact that tuning shifts develop to presentation of tone alone is a major reason for concluding that the echolocating bat is not a good model for general mammalian auditory learning and plasticity.

An extensive literature beginning in the 1960s attests to the fact that repeatedly presenting a sound by itself leads to decrements in neural response from the inferior colliculus (IC) to the auditory cortex. When appropriately tested, such decrements can be attributed to habituation, i.e., learning to lessen or stop responding to a stimulus that has no other behavioral consequences (Sokolov 1963; Thompson and Spencer 1966; Fig. 2). Table 2 summarizes a representative sample of such studies. Note that the findings of neural response decrement have been found consistently and in a wide variety of taxa, including humans. In stark contrast to prior findings, Suga finds increased responses and frequency tuning shifts to the repeated stimulus in the big brown bat (Eptesicus fuscus) (e.g., Gao and Suga 1998), a characteristic basic to his studies and theorizing.

Suga argues that "habituation did not interfere with the BF shifts," but that is not the point. The point made in the target paper is that increased responses and tuning shifts toward/to the repeated frequency are unique to the big brown bat. Why this bat develops shifts directed to the repeated frequency is unknown but may reflect the fact that the sounds are actually echolocating stimuli (brief, high-frequency pulses) rather than steady pure tones. The latter have no ecological significance and thus have been widely used in studies of learning because behavioral relevance can be attached to them arbitrarily. In contrast, echolocating sounds are likely to have ecological significance to echolocating bats. Thus, tuning shifts may reflect retuning the auditory system to emphasize their processing. In any event, the finding of shifts rather than decrements, which is not in dispute, renders this animal a poor general mammalian model for auditory-based learning.

\section{Muscimol cortical inactivation effects [1]}

Suga's original model requires that the tonal CS and shock US are projected from A1 and the primary somatosensory cortex (S1), 
Table 1. Electrophysiological studies of the MGm/PIN complex during behavioral conditioning

\begin{tabular}{llc}
\hline Reference & Subject & Associative plasticity? \\
\hline Gabriel et al. (1975) & Rabbit & Yes \\
Gabriel et al. (1976) & Rabbit & Yes \\
Disterhoft and Stuart (1976) & Rat & Yes \\
Ryugo and Weinberger (1978) & Cat & Yes \\
Birt et al. (1979) & Rat & Yes \\
Birt and Olds (1981) & Rat & Yes \\
Weinberger (1982) & Cat & Yes \\
Jarrell et al. (1986) & Rabbit & Yes \\
LeDoux (1986) & Rat & Yes \\
Edeline et al. (1988) & Rat & Yes \\
Supple and Kapp (1989) & Rabbit & Yes \\
Edeline et al. (1990) & Rat & Yes \\
Edeline (1990) & Rat & Yes \\
Edeline and Weinberger (1992) & Guinea pig & Yes \\
Hennevin et al. (1992) & Rat & Yes \\
Lennartz and Weinberger (1992) & Guinea pig & Yes \\
Hennevin et al. (1993) & Rat & Yes \\
McEchron et al. (1995) & Rabbit & Yes \\
McEchron et al. (1996) & Rabbit & Yes \\
O'Connor et al. (1997) & Rabbit & Yes \\
Hennevin et al. (1998) & Rat & Yes \\
Maho and Hennevin (2002) & Rat & Yes \\
Talk et al. (2004) & Rabbit & Yes \\
Hennevin and Maho (2005) & Rat & Yes \\
Morris et al. (1998) & Human & Yes \\
\hline
\end{tabular}

aPET neuroimaging, subnucleus of MG not identifiable.

respectively, to converge in association cortex (Fig. 1A) (Suga and Ma 2003). Aside from the fact that fear conditioning does not require any cerebral cortex (for review, see Weinberger 2007), Suga and colleagues relied on muscimol inactivation of the primary somatosensory cortex to conclude that this region was essential for conditioning and tuning plasticity. The problem is that radiolabeling studies of muscimol diffusion reveal a spread of inactivation of several millimeters for even smaller doses (Edeline et al. 2002). However, as S1 in the big brown bat is practically touching A1, the latter could have also been inactivated as well. To contest this, Suga and colleagues present figures showing no change in A1. They also stated that application at a dorsalposterior region (presumed to be visual cortex) was without effect on A1. There are two reasons why workers remain skeptical of their conclusions. First, no group data or statistical evaluations have ever been presented, only exemplar figures. Second, application of muscimol over the visual cortex would be at a greater distance from A1 than application in $\mathrm{S} 1$, and also any ventrolateral diffusion would pass posterior to A1 (Fig. $3)$. However, if statistical verification of the claim that $\mathrm{S} 1$ is essential for conditioning is forthcoming, then the findings will support the view that the big brown bat differs from other mammals in its reliance upon the cerebral cortex for fear conditioning.

\section{Thalamic reticular nucleus [2]}

The Suga model holds that the putative positive feedback loop between the auditory cortex and inferior colliculus is terminated by the thalamic reticular nucleus (TRN), which inhibits the ventral medial geniculate nucleus (MGv). I pointed out that $\mathrm{A} 1$ continues to receive good auditory information during and after learning. Suga thinks this is overly simplistic and appeals to a suggestion by Villa et al. (1991) regarding the TRN and adaptive filtering. Villa may well be correct, but Suga's model would require the auditory cortex to "instruct" the TRN not to permit the extra tone-evoked spikes induced by learning (from the inferior colliculus) to be blocked at the MGv. How might the auditory cortex distinguish between the extra spikes caused by learning from those spikes that are not so caused? It would be appropriate for Suga to explicate the TRN component of his model rather than invoke the TRN carte blanche.

Lack of behavioral validation of associative conditioning [5] Suga and colleagues had provided no behavioral validation of associative behavioral conditioning to tone since their first report and used a fixed intertrial interval, which is subject to temporal conditioning (Gao and Suga 1998). Suga has recently provided cardiac conditioning (bradycardia) records that appear to substantiate his claim of associative learning. This is most welcome. However, the findings are confusing. The figures (Fig. 2, Suga [2008]) show time (min) on the abscissa, which would indicate change in heart rate across a 30-min session. If so, then the cardiac conditioned response is not normal; it is dissipating over trials, reaching its maximum effect slightly less than halfway through a 30-min session, and returning to baseline by the end of the session (Fig. 2A in Suga 2008).

\section{Proposed experiments}

In an Appendix, Suga suggests that my lab perform experiments on the MGm/PIN, including stimulation and inactivation, to test his hypothesis that the MGm/PIN is involved only in pseudoconditioning, not association, and cortical shifts. It's already known that sound paired with stimulation of the MGm/PIN produces long-term potentiation of sound-elicited responses in A1 (Weinberger et al. 1995). Nevertheless, although it is unclear why Suga has not performed such studies, we will be happy to do them in parallel with his lab provided that (1) sufficient funds become available and (2) Suga explains why he ignores/rejects the overwhelming evidence that the MGm/PIN develops associative plasticity.

He also wants us to perform experiments on temporal conditioning and muscimol inactivation of somatosensory cortex.

\section{A. Conditioning}

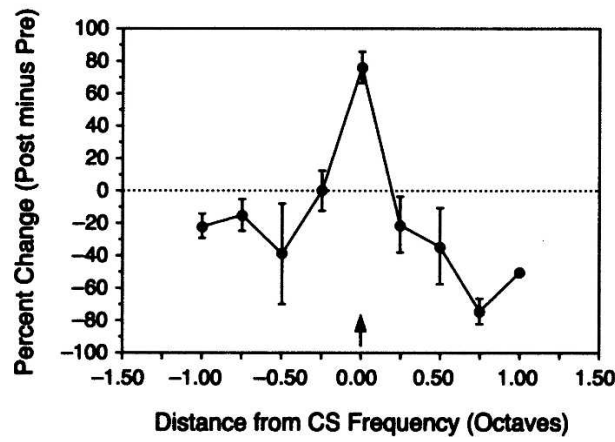

\section{B. Habituation}

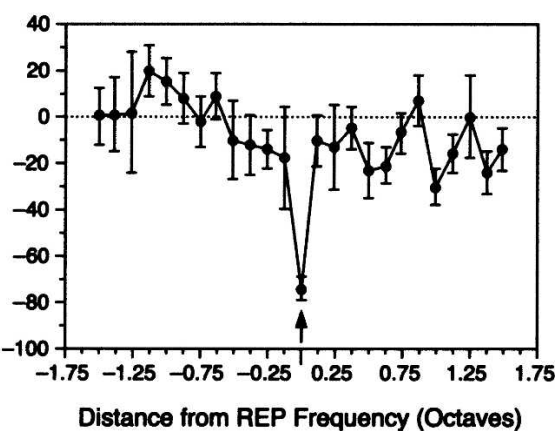

Figure 2. Retuning in the primary auditory cortex during learning. Changes in frequency tuning (mean \pm SD) expressed as receptive field (RF) differences (post - pre) for conditioning $(A)$ and habituation $(B)$. Values are expressed as distance (octaves) from the frequency of the paired tone (CS) for conditioning and the repeated tone for habituation. Note the specificity of the tuning plasticity, with a large increase only at the CS frequency for conditioning and marked decrement at the repeated frequency for habituation. Reprinted from Weinberger (1995), with permission from MIT Press (C) 1995. 
Table 2. Electrophysiological studies of the auditory vortex during repetition of sound

\begin{tabular}{llc}
\hline Reference & Subject & Decrement? \\
\hline Marsh et al. (1961) & Cat & Yes \\
Marsh and Worden (1964) & Cat & Yes \\
Dunlop et al. (1964) & Cat & Yes \\
Dunlop et al. (1966) & Cat & Yes \\
Buchwald et al. (1966) & Cat & Yes \\
Hall (1968) & Rat & Yes \\
Cook et al. (1968) & Cat & Yes \\
Wickelgren (1968) & Cat & Yes \\
Halas and Beardsley (1969) & Cat & Yes \\
Kitzes and Buchwald (1969) & Cat & Yes \\
Holstein et al. (1969) & Cat & Yes \\
Halas et al. (1970) & Cat & Yes \\
Webster and Bock (1971) & Rat & Yes \\
Webster and Aitkin (1971) & Cat & Yes \\
Weinberger et al. (1975) & Cat & Yes \\
Westenberg et al. (1976) & Cat & Yes \\
Westenberg and Weinberger (1976) & Cat & Yes \\
Condon and Weinberger (1991) & Guinea pig & Yes \\
Maho et al. (1995) & Rat & Yes \\
Ulanovky et al. (2003) & Cat & Yes \\
Sakai (2007) & Rat & Yes \\
Rosburg et al. (2002) & Human & Yes \\
Rosburg et al. (2006) & Human & Yes \\
Gao and Suga (1998) & Bat & No \\
Gao and Suga (2000) & Bat & No \\
\hline
\end{tabular}

However, as Suga has made the claims that his data are unblemished, it is customary for the claimant to provide evidence to support his own claims.

Suga also wants us to determine if tuning shifts develop to repeated acoustic stimulation and if there is habituation to other frequencies. This has already been done, as discussed above (see also Fig. 1B). The answers are "no" and "no."

Finally, Suga wants us to determine ". . . whether the BF shift of the MGBm can be elicited by auditory fear conditioning without the collicular BF shift." This request is truly confusing because Suga holds that there are no associative tuning shifts in the MGBm (MGm/PIN), as he states that it is involved only in pseudoconditioning, But as he now apparently hypothesizes that shifts in the inferior colliculus cause shifts in the MGBm, it is incumbent upon him to test this hypothesis.

\section{Conclusions}

Suga and his associates are performing an important service by their investigations of the functions of the auditory system's descending connections. However, their approach is too focused on supporting a highly problematic model. This exchange of letters

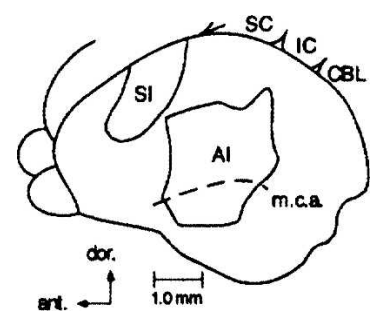

Figure 3. Diagrammatic representation of the left cerebral hemisphere (dorsolateral surface view) of the big brown bat (E. fuscus). Note the close proximity of the primary somatosensory cortex to the primary auditory cortex. The latter is within the limits of diffusion of muscimol applied to the former. (A1) Primary auditory cortex, (CBL) cerebellum, (IC) inferior colliculus, (m.c.a.) middle cerebral artery, (S1) primary somatosensory, (SC) superior colliculus. Reprinted from Gao and Suga (1998), with permission from the National Academy of Sciences of the USA () 1998. does not merely constitute a technical dispute or reflect a chaotic state of knowledge in associative representational plasticity in the auditory system. Rather, it documents two distinct approaches to behavioral neuroscience. Suga's letter reveals a failure to acknowledge prior findings that are inconsistent with his model and a commitment to claims at the expense of logic. Both are evident in arguments against the MGm/PIN in associative learning and plasticity on the one hand, and for the echolocating bat as a general mammalian model on the other hand. The canons of science require the opposite approach.

\section{Acknowledgments}

This research was funded by a research grant from the National Institute of Deafness and Other Communication Disorders, DC02938. I thank Drew Headley for helpful comments.

\section{References}

Bakin, J.S. and Weinberger, N.M. 1996. Induction of a physiological memory in the cerebral cortex by stimulation of the nucleus basalis. Proc. Natl. Acad. Sci. 93: 11219-11224.

Birt, D. and Olds, M. 1981. Associative response changes in lateral midbrain tegmentum and medial geniculate during differential appetitive conditioning. J. Neurophysiol. 46: 1039-1055.

Birt, D., Nienhuis, R., and Olds, M. 1979. Separation of associative from non-associative short latency changes in medial geniculate and inferior colliculus during differential conditioning and reversal in rats. Brain Res. 167: 129-138.

Bjordahl, T.S., Dimyan, M.A., and Weinberger, N.M. 1998. Induction of long-term receptive field plasticity in the auditory cortex of the waking guinea pig by stimulation of the nucleus basalis. Behav. Neurosci. 112: 467-479.

Buchwald, J.S., Halas, E.S., and Schramm, S. 1966. Changes in cortical and subcortical unit activity during behavioral conditioning. Physiol. Behav. 1: 11-22.

Condon, C.D. and Weinberger, N.M. 1991. Habituation produces frequency-specific plasticity of receptive fields in the auditory cortex. Behav. Neurosci. 105: 416-430.

Cook, J.D., Ellinwood Jr., E.H., and Wilson, W.P. 1968. Auditory habituation at primary cortex as a function of stimulus rate. Exp. Neurol. 21: 167-175.

Disterhoft, J.F. and Stuart, D.K. 1976. Trial sequence of changed unit activity in auditory system of alert rat during conditioned response acquisition and extinction. J. Neurophysiol. 39: 266-281.

Dunlop, C.W., Webster, W.R., and Day, R.H. 1964. Amplitude changes of evoked potentials at the inferior colliculus during acoustic habituation. J. Aud. Res. 4: 159-169.

Dunlop, C.W., Webster, W.R., and Rodger, R.S. 1966. Amplitude changes of evoked potentials in the auditory system of unanesthetized cats during acoustic habituation. J. Aud. Res. 6: $47-66$.

Edeline, J.-M. 1990. Frequency-specific plasticity of single unit discharges in the rat medial geniculate body. Brain Res. 529: 109-119.

Edeline, J.-M. and Weinberger, N.M. 1992. Associative retuning in the thalamic source of input to the amygdala and auditory cortex: Receptive field plasticity in the medial division of the medial geniculate body. Behav. Neurosci. 106: 81-105.

Edeline, J.-M., Dutrieux, G., and Neuenschwander-el Massioui, N. 1988. Multiunit changes in hippocampus and medial geniculate body in free-behaving rats during acquisition and retention of a conditioned response to a tone. Behav. Neural Biol. 50: 61-79.

Edeline, J.-M., Neuenschwander-El Massioui, N., and Dutrieux, G. 1990. Frequency-specific cellular changes in the auditory system during acquisition and reversal of discriminative conditioning. Psychobiology 18: $382-393$.

Edeline, J.-M., Hars, B., Hennevin, E., and Cotillon, N. 2002. Muscimol diffusion after intracerebral microinjections: A reevaluation based on electrophysiological and autoradiographic quantifications. Neurobiol. Learn. Mem. 78: 100-124.

Gabriel, M., Saltwick, S.E., and Miller, J.D. 1975. Conditioning and reversal of short-latency multiple-unit responses in the rabbit medial geniculate nucleus. Science 189: 1108-1109.

Gabriel, M., Miller, J.D., and Saltwick, S.E. 1976. Multiple-unit activity of the rabbit medial geniculate nucleus in conditioning, extinction, and reversal. Physiol. Psychol. 4: 124-134. 
Gao, E. and Suga, N. 1998. Experience-dependent corticofugal adjustment of midbrain frequency map in bat auditory system. Proc. Natl. Acad. Sci. 95: 12663-12670.

Gao, E. and Suga, N. 2000. Experience-dependent plasticity in the auditory cortex and the inferior colliculus of bats: Role of the corticofugal system. Proc. Natl. Acad. Sci. 97: 8081-8086.

Halas, E.S. and Beardsley, J.V. 1969. A factor analysis of neuronal responses during habituation in cats. Psychol. Rec. 19: 47-52.

Halas, E.S., Beardsley, J.V., and Sandlie, M.E. 1970. Conditioned neuronal responses at various levels in conditioning paradigms. Electroencephalogr. Clin. Neurophysiol. 28: 468-477.

Hall, R.D. 1968. Habituation of evoked potentials in the rat under conditions of behavioral control. Electroencephalogr. Clin. Neurophysiol. 24: 155-165.

Hennevin, E. and Maho, C. 2005. Fear conditioning-induced plasticity in auditory thalamus and cortex: To what extent is it expressed during slow-wave sleep? Behav. Neurosci. 119: 1277-1289.

Hennevin, E., Maho, C., and Hars, B. 1992. Learning-induced increase of tone-evoked response in the auditory thalamus during paradoxical sleep. Abs. No. 445.1. Soc. Neurosci. Abstr. 18: 1064.

Hennevin, E., Maho, C., Hars, B., and Dutrieux, G. 1993. Learning-induced plasticity in the medial geniculate nucleus is expressed during paradoxical sleep. Behav. Neurosci. 107: 1018-1030.

Hennevin, E., Maho, C., and Hars, B. 1998. Neuronal plasticity induced by fear conditioning is expressed during paradoxical sleep: Evidence from simultaneous recordings in the lateral amygdala and the medial geniculate in rats. Behav. Neurosci. 112: 839-862.

Holstein, S.B., Buchwald, J.S., and Schwafel, J.A. 1969. Progressive changes in auditory response patterns to repeated tone during normal wakefulness and paralysis. Brain Res. 16: 133-148.

Jarrell, T.W., Gentile, C.G., McCabe, P.M., and Schneiderman, N. 1986 The role of the medial geniculate region in differential Pavlovian conditioning of bradycardia in rabbits. Brain Res. 374: 126-136.

Ji, W. and Suga, N. 2003. Development of reorganization of the auditory cortex caused by fear conditioning: Effect of atropine. $J$. Neurophysiol. 90: 1904-1909.

Ji, W. and Suga, N. 2007. Cortical tone-specific plasticity elicited by conditioning and cortical non-specific plasticity elicited by pseudoconditioning depend on different neuromodulators. Prog. No. 174.4. In 2007 Neuroscience Meeting Planner. Society for Neuroscience, Washington DC.

Ji, W., Gao, E., and Suga, N. 2001. Effects of acetylcholine and atropine on plasticity of central auditory neurons caused by conditioning in bats. J. Neurophysiol. 86: 211-225.

Ji, W., Suga, N., and Gao, E. 2005. Effects of agonists and antagonists of NMDA and ACh receptors on plasticity of bat auditory system elicited by fear conditioning. J. Neurophysiol. 94: 1199-1211.

Kilgard, M.P. and Merzenich, M.M. 1998. Cortical map reorganization enabled by nucleus basalis activity. Science 279: 1714-1718.

Kitzes, M. and Buchwald, J. 1969. Progressive alterations in cochlear nucleus, inferior colliculus, and medial geniculate responses during acoustic habituation. Exp. Neurol. 25: 85-105.

LeDoux, J.E. 1986. Sensory systems and emotion: A model of affective processing. Integr. Psychiatry 4: 237-243.

Lennartz, R.C. and Weinberger, N.M. 1992. Frequency-specific receptive field plasticity in the medial geniculate body induced by Pavlovian fear conditioning is expressed in the anesthetized brain. Behav. Neurosci. 106: 484-497.

Maho, C. and Hennevin, E. 2002. Appetitive conditioning-induced plasticity is expressed during paradoxical sleep in the medial geniculate, but not in the lateral amygdala. Behav. Neurosci. 116: $807-823$.

Maho, C., Hars, B., Edeline, J.-M., and Hennevin, E. 1995. Conditioned changes in the basal forebrain: Relations with learning-induced cortical plasticity. Psychobiology 23: 10-25.

Marsh, J.T. and Worden, F.G. 1964. Auditory potentials during acoustic habituation: Cochlear nucleus, cerebellum and auditory cortex. Electroencephalogr. Clin. Neurophysiol. 17: 677-684.

Marsh, J.T., McCarthy, D.A., Sheatz, G., and Galambos, R. 1961. Amplitude changes in evoked auditory potentials during habituation and conditioning. Electroencephalogr. Clin. Neurophysiol. 13: 224-234.

McEchron, M.D., McCabe, P.M., Green, E.J., Llabre, M.M., and Schneiderman, N. 1995. Simultaneous single unit recording in the medial nucleus of the medial geniculate nucleus and amygdaloid central nucleus throughout habituation, acquisition, and extinction of the rabbit's classically conditioned heart rate. Brain Res. 682: $157-166$.

McEchron, M.D., Green, E.J., Winters, R.W., Nolen, T.G., Schneiderman, N., and McCabe, P.M. 1996. Changes of synaptic efficacy in the medial geniculate nucleus as a result of auditory classical conditioning. J. Neurosci. 16: 1273-1283.

Morris, J.S., Friston, K.J., and Dolan, R.J. 1998. Experience-dependent modulation of tonotopic neural responses in human auditory cortex. Proc. R. Soc. Lond. B. Biol. Sci. 265: 649-657.

O'Connor, K.N., Allison, T.L., Rosenfield, M.E., and Moore, J.W. 1997. Neural activity in the medial geniculate nucleus during auditory trace conditioning. Exp. Brain Res. 113: 534-556.

Rosburg, T., Haueisen, J., and Sauer, H. 2002. Habituation of the auditory evoked field component N100m and its dependence on stimulus duration. Clin. Neurophysiol. 113: 421-428.

Rosburg, T., Trautner, P., Boutros, N.N., Korzyukov, O.A., Schaller, C., Elger, C.E., and Kurthen, M. 2006. Habituation of auditory evoked potentials in intracranial and extracranial recordings. Psychophysiology 43: 137-144.

Ryugo, D.K. and Weinberger, N.M. 1978. Differential plasticity of morphologically distinct neuron populations in the medical geniculate body of the cat during classical conditioning. Behav. Biol. 22: $275-301$.

Sakai, M. 2007. Habituation enhances auditory perceptual capacity in adult rats. Behav. Brain Res. 181: 1-11.

Sokolov, E.N. 1963. Perception and the conditioned reflex (transl. S.W. Waydenfeld). Pergamon Press, New York. (Translation of Sokolov, E.N. 1958. Vospriiatie i uslovnyi refleks. Moscow University, Moscow.)

Suga, N. 2008. The neural circuit for tone-specific plasticity in the auditory system elicited by auditory fear conditioning. Learn. Mem. (this issue) doi: 10.1101/lm.791408.

Suga, N. and Ma, X. 2003. Multiparametric corticofugal modulation and plasticity in the auditory system. Nat. Rev. Neurosci. 4: 783-794.

Suga, N., Ji, W., and Ma, X. 2004. Criticisms of 'Specific long-term memory traces in primary auditory cortex'. Nat. Rev. Neurosci. 5: doi: 10.1038/nrn1366-c3.

Supple Jr., W.F. and Kapp, B.S. 1989. Response characteristics of neurons in the medial component of the medial geniculate nucleus during Pavlovian differential fear conditioning in rabbits. Behav. Neurosci. 103: $1276-1286$.

Talk, A., Kashef, A., and Gabriel, M. 2004. Effects of conditioning during amygdalar inactivation on training-induced neuronal plasticity in the medial geniculate nucleus and cingulate cortex in rabbits (Oryctolagus cuniculus). Behav. Neurosci. 118: 944-955.

Thompson, R.F. and Spencer, W.A. 1966. Habituation: A model phenomenon for the study of neuronal substrates of behavior. Psychol. Rev. 73: 16-43.

Ulanovsky, N., Las, L., and Nelken, I. 2003. Processing of low-probability sounds by cortical neurons. Nat. Neurosci. 6: 391-398.

Villa, A.E., Rouiller, E.M., Simm, G.M., Zurita, P., de Ribaupierre, Y., and de Ribaupierre, F. 1991. Corticofugal modulation of the information processing in the auditory thalamus of the cat. Exp. Brain. Res. 86: $506-517$.

Webster, W.R. and Aitkin, L.M. 1971. Evoked potential and single unit studies of neural mechanisms underlying the effects of repetitive stimulation in the auditory pathway. Electroencephalogr. Clin. Neurophysiol. 31: 581-592.

Webster, W.R. and Bock, G.R. 1971. The effects of repetitive stimulation on the rat inferior colliculus. Electroencephalogr. Clin. Neurophysiol. 30: 331-336.

Weinberger, N.M. 1982. Sensory plasticity and learning: The magnocellular medial geniculate nucleus of the auditory system. In Conditioning: Representation of involved neural functions (Advances in behavioral biology, vol. 26) (ed. C.D. Woody), pp. 697-710. Plenum Press, New York.

Weinberger, N.M. 1995. Retuning the brain by fear conditioning. In The cognitive neurosciences (ed. M.S. Gazzaniga), Chap. 71, pp. 1071-1089. MIT Press, Cambridge, MA.

Weinberger, N.M. 1998. Physiological memory in primary auditory cortex: Characteristics and mechanisms. Neurobiol. Learn. Mem. 70: $226-251$.

Weinberger, N.M. 2004a. Consequences of failures to meet standards in learning and memory. Nat. Rev. Neurosci. 5: doi: $10.1038 / \mathrm{nrn} 1366-\mathrm{c} 4$

Weinberger, N.M. 2004b. Specific long-term memory traces in primary auditory cortex. Nat. Rev. Neurosci. 5: 279-290.

Weinberger, N.M. 2007. Associative representational plasticity in the auditory cortex: A synthesis of two disciplines. Learn. Mem. 14: 1-16.

Weinberger, N.M., Oleson, T.D., and Ashe, J.H. 1975. Sensory system neural activity during habituation of the pupillary orienting reflex. Behav. Biol. 15: 283-301.

Weinberger, N.M., Ashe, J.H., Metherate, R., McKenna, T.M., Diamond, D.M., and Bakin, J. 1990a. Retuning auditory cortex by learning: A preliminary model of receptive field plasticity. Concepts Neurosci. 1: $91-132$.

Weinberger, N.M., Ashe, J.H., Metherate, R., McKenna, T.M., Diamond, D.M., Bakin, J.S., Lennartz, R.C., and Cassady, J.M. 1990b. Neural adaptive information processing: A preliminary model of receptive 
field plasticity in auditory cortex during Pavlovian conditioning. In Learning and computational neuroscience: Foundations of adaptive networks (eds. M. Gabriel and J. Moore), pp. 91-138. MIT Press, Cambridge, MA.

Weinberger, N.M., Javid, R., and Lepan, B. 1995. Heterosynaptic long-term facilitation of sensory-evoked responses in the auditory cortex by stimulation of the magnocellular medial geniculate body in guinea pigs. Behav. Neurosci. 109: 10-17.

Westenberg, I.S. and Weinberger, N.M. 1976. Evoked potential decrements in auditory cortex. II. Critical test for habituation.
Electroencephalogr. Clin. Neurophysiol. 40: 356-369.

Westenberg, I.S., Paige, G., Golub, B., and Weinberger, N.M. 1976. Evoked potential decrements in auditory cortex. I. Discrete-trial and continual stimulation. Electroencephalogr. Clin. Neurophysiol. 40: $337-355$.

Wickelgren, W.O. 1968. Effect of acoustic habituation on click-evoked responses in cats. J. Neurophysiol. 31: 777-784.

Received January 17, 2008; accepted in revised form January 31, 2008. 


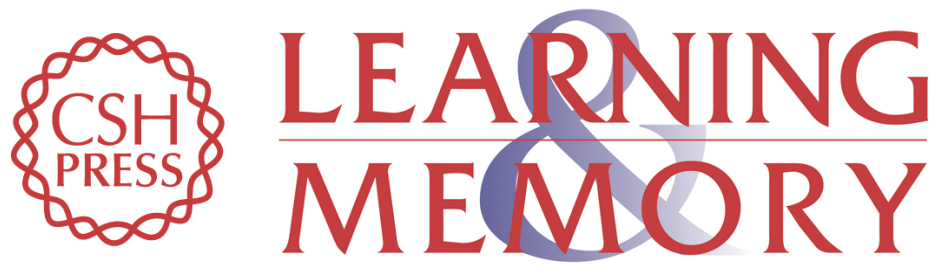

\section{Retuning the brain by learning, literature, and logic: Reply to Suga}

Norman M. Weinberger

Learn. Mem. 2008, 15:

Access the most recent version at doi:10.1101//m.914208

References This article cites 65 articles, 8 of which can be accessed free at: http://learnmem.cshlp.org/content/15/4/202.full.html\#ref-list-1

License

Email Alerting Receive free email alerts when new articles cite this article - sign up in the box at the Service top right corner of the article or click here. 